\title{
ASSESSING DEPRECIATION FOR VALUATION PURPOSES - A DECOMPOSITIONAL APPROACH
}

\author{
F. Gyamfi-Yeboah and J. Ayitey \\ Department of Land Economy \\ Kwame Nkrumah University of Science and Technology, \\ Kumasi, Ghana
}

\begin{abstract}
In valuing property one method that is commonly adopted in situations where market evidence is non-existent is the Depreciated Replacement Cost method. As the name suggests, this involves estimating the replacement cost as new of the property, which is the subject matter of the valuation, and making allowances for accrued depreciation. The allowance made for depreciation is important as it allows for the estimation of value that reflects the current state of the property. The estimation of depreciation for valuation purposes has been the subject for a number of empirical studies. There is however no consensus within the valuation profession as to which approach to estimating accrued depreciation addresses the key elements that are of concern to the valuer viz; age, condition and functional obsolescence. The paper proposes one such approach that incorporates all these elements in the estimation of accrued depreciation for valuation purposes. The approach first considers the individual causes of depreciation separately and uses different methods to estimate accrued depreciation for each of the causes of depreciation. Total accrued depreciation is then estimated by first taking account of curable physical depreciation and then age and functional obsolescence. The approach proposed presents a basis for a more comprehensive discussion and a subsequent adoption of a common methodology valuers can rely on to estimate depreciation.
\end{abstract}

Keywords: Depreciation, Valuation, Depreciated Replacement Cost

\section{INTRODUCTION}

The value of real estate or property is arrived at through a number of methods viz; the income or investment method, the cost, residual, market comparison and the profit methods. The choice of a method depends on the purpose and basis of valuation as well as the data or information available to the valuer. The purposes for which valuations may be undertaken include sale/purchases, insurance, rating, compensa- tion, mortgage, auction, accounting among others. The purpose of a valuation will clearly influence the basis that would be adopted in estimating value. The basis of valuation could be one the following; Open Market Value (O.M.V), Forced Sale Value and Valuation subject to statutory rules.

A method that is commonly adopted in situations where market evidence is non-existent is 
the Depreciated Replacement Cost. As the name suggests, this involves estimating the Replacement cost as new of the property, which is the subject matter of the valuation, and making allowances for accrued depreciation. The allowance made for depreciation is important as it allows for the estimation of value that reflects the current state of the property.

There are a number of approaches by which depreciation, either for accounting or valuation purposes, can be estimated. Each method has its inherent advantages and problems. For instance, a method that is commonly adopted among accountants is the straight-line or agelife method. Though it is simple and easy to adopt, it has the disadvantage of not correctly modeling the true impact of depreciation during the life of an asset. It is imperative to note that unlike the depreciation adopted for accounting purposes, the valuer, in adopting depreciation in the Depreciated Replacement Cost (DRC) method, is supposed to arrive at a value that represents the current market value of the property. This requirement obviously rules out the possibility of adopting such simplistic methods as the straight-line method of depreciation.

The approach that is adopted in many valuation exercises is to examine the property in question and take notes of its age, physical deterioration and obsolescence. The valuer then, makes a judgment using his professional expertise, to finally arrive at the rate of depreciation. In doing this, valuation professionals may rely on different models or mathematical relationships to guide them in estimating the rate of depreciation. There is however, no consensus on the model or approach which when used will help reduce the level of variations in the opinion of appraisers.

This paper seeks to propose an approach which can guide professional valuers in the process of estimating the level of depreciation for any particular property.

THE CONCEPT OF PROPERTY DEPRECIATION AND ITS ESTIMATION

Baum (1991) defines depreciation as a loss in the existing value of property and attributes the causes to physical deterioration, functional obsolescence or aesthetic obsolescence. Mansfield (2000) also notes that property-based depreciation is the result of two negative processes, physical deterioration and obsolescence. Barreca (1999) classifies depreciation into three classes namely physical depreciation, functional depreciation and other economic losses. These three views of depreciation obviously have something in common and that is the fact that depreciation is the result of physical deterioration, functional and economic obsolescence. This position is quite consistent with the provision in the Guidance Notes (Issued by the Ghana Institution of Surveyors) on valuation practice in Ghana. The Guidance Notes provide under Section 2.1.4(b) that valuers, in using the Depreciated Replacement Cost, should make a deduction from the Replacement Cost, of the building to allow for age, condition and functional obsolescence. The only difference between the provision in the Guidance Notes and the view expressed by these authors is that the former treats age as a separate cause of depreciation while these authors incorporate age into the other causes of depreciation. What is important, however, is that there is a general consensus on the causes of depreciation at least at a very broad level.

The methods for estimating depreciation for valuation purposes have been the focus of a number of empirical studies. A method that is very common and is widely used both in the valuation and accounting professions is the agelife method, also known as the straight-line method. However, in a study by Hulten and Wycoff (1978), it was concluded that for all four types of properties studied (that is offices, retail stores, factories and warehouses) the straight-line method should be rejected and that an alternative path of depreciation to that is initially more accelerated than the straight-line (that is convex to the origin) should be accepted. Also, Follain and Malpezzi (1980) in a study that relates specifically to single-family residential units draw a similar conclusion to that of Hulten and Wycoff (1978). 
Jones et al (1981) in sharp contrast to the results of Hulten and Wycoff and Follain and Malpezzi find in their study of single-family housing, that the depreciation model should be concave to the origin and allow for the depreciation rate to be small at first and more pronounced later. In a study on office buildings, Taubman and Rashe (1969) reach a similar conclusion to that of Jones et al. Connaday and Sunderman (1986) using a sample of singlefamily residential properties conclude that the path of depreciation that is supported by the empirical evidence is one that is concave to the origin (that is initially less rapid than the straight-line). They further state that, of the standard paths of depreciation often suggested, the reverse sum of the years' digits path most closely approximates the path indicated as appropriate by the empirical results of their study.

It is evident from the above that although all the empirical studies rejected depreciation by the straight-line method, there is no consensus as to what the right path should be. Two paths are suggested by these studies; one that is convex to the origin and another that is concave to the origin with both approximated by the sum of the years' digits and the reverse of the sum of the years' digits respectively. It is important to note the data used for these analyses were from particular areas and different property types and thus the results cannot be universally applied.

\section{THE DECOMPOSITIONAL MODEL Development of the Model}

It is important to state from the outset that the model being proposed is not meant to be a substitute to the use of the valuer's experience and judgment. Rather it is meant to serve as a tool that will guide valuers in their use of such experience and judgments and also to generate a debate aimed at improving the quality of service delivery.

In developing the model, the three components of depreciation viz; age, physical deterioration and obsolescence are considered separately. Total accrued depreciation of an asset is then expressed as a function of these three components. How do these interact to give total accrued depreciation? To what extent does each one of these contribute to total accrued depreciation of an asset and how should this be accounted for? These are the critical questions that engage the mind in developing the model.

To begin with, we consider the three components of depreciation individually;

\section{Age}

Most assets have limited lives, which imply that there will come a time when such assets will be no more. For such assets, it stands to reason that no matter how well they are maintained, they will waste away at some point. Thus the impact of time on the life of an asset in terms of depreciation is inevitable.

It is important to note that although the lapse of time is necessary for the other causes of depreciation to take effect, time by itself is a cause of depreciation and must therefore be given a separate treatment. This becomes evident when one considers the fact that there are some aspects of physical deterioration that are incurable. These kinds of incurable depreciation elements are better taken account of under the age component.

There are quite a number of methods of estimating depreciation that use the age and the useful economic life of an asset. These include the age-life, sum of the years' digits and the reverse sum of the years' digits among others. Useful economic life of assets varies and depends on a number of factors such as quality of construction and type of construction material used as well as the location characteristics of the property. Currently, there appears to be no empirical evidence that indicates the useful economic life of buildings in Ghana but such evidence exists in countries such as the United States. See Wenzlick (1953), Corgel and Smith (1981). These studies put the effective economic lives of buildings in specific location at between 75 and 88 years.

In certain circumstances, it becomes necessary to use the effective age of property rather than

48 Journal of Science and Technology, Vol. 29, No. 2, Aug., 2009 
its actual age. For instance, property may have an actual age of 5 years but may be so intensively used that its effective age could well be over 7 years. The use of effective age becomes more compelling when property wears out faster or slower over time compared to other similar properties.

The age-life method estimates accrued depreciation on the premise that an asset will depreciate by the same amount every year. This method though straightforward and simple has been found not to correctly model the path of depreciation over the life of the asset. The question to pose is whether relying on such a method will assist the valuer to estimate accurately the market value of an asset. The agelife otherwise known as Straight-line depreciation is given by the formula below;

\section{Accrued Depreciation $=($ Age $/$ Useful Economic} life) $x$ Replacement Cost

The sum of the years' digit is another age based method which estimates depreciation on the premise that an asset will depreciate at a higher rate during the initial years of the asset's life than at latter years. The path of depreciation implied by this method as shown in figure 1 is supported by the empirical studies conducted by Hulten and Wycoff (1978) and Follain and Malpezzi (1980). It is given by the formula;

$$
\text { Accrued Depreciation }=1-\frac{N(N-1)}{\text { Life }(\text { Life }+1)}
$$

A third method that also incorporates the age variable is the Reverse Sum of the Years' digit. This method presupposes that depreciation is slower initially and more pronounced later. The path of depreciation implied by this method as depicted in figure 2 below is supported by a number of empirical studies (see Jones et al (1981), Taubman and Rashe (1969) and Connaday and Sunderman (1986)). This is given by the formula below.

Accumulated Depreciation $=\frac{\text { Age }(\text { Age }+1)}{\text { Life }(\text { Life }+1)}$

It is evident from the above that the method of depreciation that closely models the impact of depreciation over the life of an asset is either the sum of the years' digits or the reverse sum of the years' digit. It must be noted that the empirical studies relied mostly on data from the US and may therefore not be a true representa-

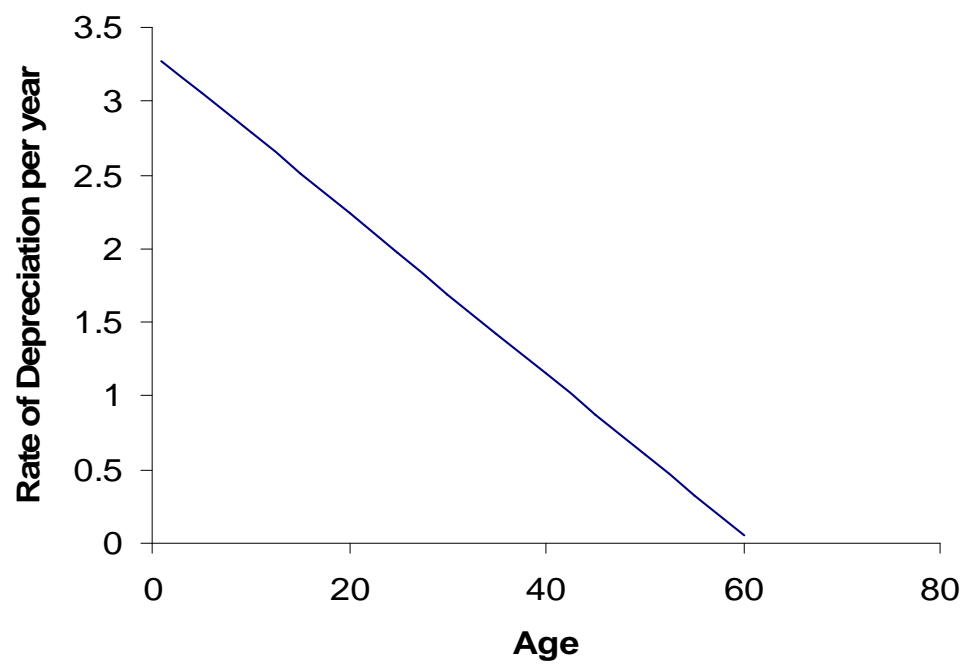

Fig. 1: Sum of the Years' Digits Depreciation path 


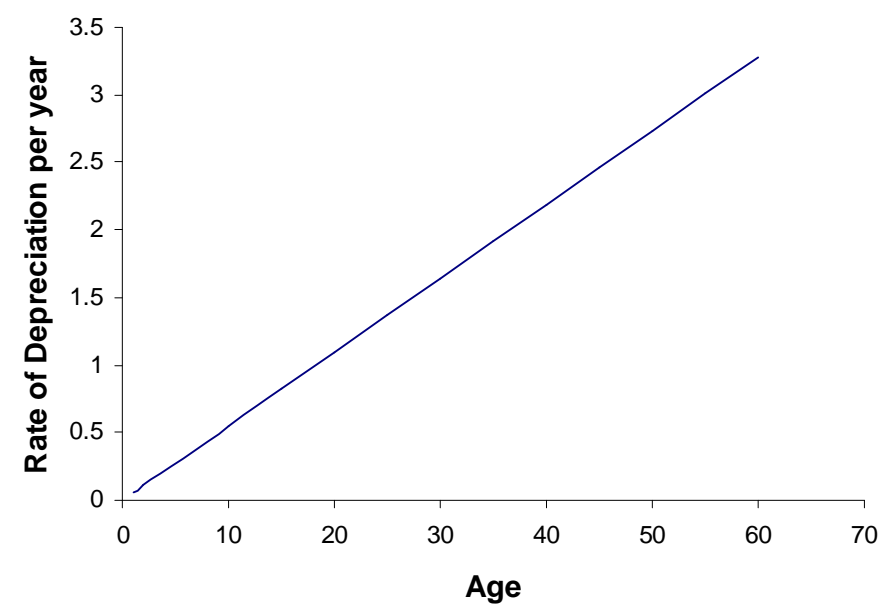

Fig. 2: Reverse Sum of the Years' Digits Depreciation Path

tive of the Ghanaian situation. There is therefore the need to carry out studies based on data from the Ghanaian market to determine which of these methods is supported by empirical evidence. Until this is done, a consensus will have to be reached on which of these methods should be adopted in valuation practice in Ghana. For the purposes of this paper however, the reverse sum of the years' digits is the assumed path of depreciation adopted.

Does age tell the entire story about depreciation? Before we answer this question, let's consider the following; two very similar properties are put up in the same year. One is well kept whiles the other is poorly maintained. If we base the estimate of depreciation solely on the age variable, the two properties will undoubtedly have the same amount for accrued depreciation. But is this really tenable given the fact that the conditions for the two properties are different? Certainly no. How can we account for the differences in the conditions of the two properties? This leads us to explore the other causes of depreciation; namely physical deterioration and obsolescence.

\section{Physical Deterioration}

Physical deterioration as a cause of depreciation is the result of wear and tear with usage and deterioration with age among others. It is important to note that there are two aspects of physical deterioration that need to be distinguished. These are curable and incurable deterioration. For the purposes of this paper whenever physical deterioration is used it means the curable component of deterioration. The incurable component of physical deterioration is taken care of under the age variable. This is to allow for a more explicit estimation of curable deterioration. This approach was adopted by Brueggeman and Fisher (2001).

There is no doubt that assets wear and tear with usage. What is critical however is how such occurrences can be accurately accounted for in the estimation of accumulated depreciation for valuation purposes. A common approach is to identify the defects in the assets which when rectified will restore the asset into a state that is comparable to a similar asset that is new. Such defects are quantified and the amount expressed as a percentage of the replacement cost as new of the property to arrive at the rate for physical depreciation.

\section{Obsolescence}

As noted by Mansfield (2000), the scope of obsolescence is wide, embracing factors that relate to the structures themselves, the particu- 
lar site the property occupies and its surrounding area, the statutory and regulatory framework and more subjective, aesthetic issues. What this means is that there is no real consensus on what the term refers to. Baxter (1971), for instance defines obsolescence as a value decline that is not caused directly by use or the passage of time. Mansfield (2000) quoting Raftery (1991) states that since obsolescence is a function of human perception and decision, the categorization of obsolescence must depend on the person making the assessment. This, in Mansfield's view potentially increases the difficulties because the opinions of investors, occupiers and researchers may be wildly divergent and unlike physical depreciation, cannot be objectively evaluated. Notwithstanding the apparent difficulty in defining obsolescence, it can be grouped into two main types; functional and external obsolescence. For the purposes of this paper however, we shall deal with only functional obsolescence for the simple reason that it is this type of obsolescence that according to the GhIS Guidance notes should be taken account of in valuations (See Guidance Note section 2.1.4(b). The merit or otherwise of this position could be the subject of a debate.

Functional depreciation is defined by Barreca (1999) as the loss in value (ie depreciation) resulting from a relative deficiency of the asset to function for its intended purpose. Such a deficiency could be the result of changing consumer expectations and the availability of new and more efficient designs among others.

It should be obvious that an objective estimation of functional depreciation will be very difficult if not impossible. This is because achieving a consensus on the extent to which property is deficient in functioning as intended will be unlikely. The suggestion here is to leave this to the judgment and experience of the appraiser. Functional obsolescence is usually a gradual process and requires time to fully become evident in a property. This makes it quite closely related to age though such a correlation is not automatic. In other words, an asset can be very old but still very functional.
An approach that has been adopted in the estimation of functional obsolescence is to estimate the extra cost that is incurred in using the property in question as compared to using a similar more efficient property (see Brueggeman and Fisher 2001). The correct estimate of functional obsolescence through this approach depends largely on the appraiser's experience in the market, his knowledge of the existence of more efficient properties and his appreciation of the functionality of properties.

\section{Total Accumulated Depreciation}

Up until this point, depreciation has been looked at in terms of its causes. What is ultimately important in the estimation of value via the cost method is total accrued depreciation. How do we estimate total accrued depreciation given the fact that none of the methods discussed so far incorporates all the causes of depreciation? The approach being proposed here is to combine the impact from the various causes of depreciation. That is to say whatever rate is arrived at as accumulated depreciation should take account of age, condition of the property (i.e. level of maintenance) and functional obsolescence.

In estimating total accumulated depreciation, we first estimate the depreciation rates for the individual causes of depreciation. In this instance, the reverse sum of the years' digits is adopted for age and functional obsolescence whiles physical depreciation (curable) is estimated using the schedule of maintenance approach. The second step is to combine these rates by taking into account the contribution of each of these to total depreciation. This involves first accounting for the curable physical depreciation before any reduction is made for incurable physical depreciation and functional obsolescence. Such an approach as explained by Brueggeman and Fisher (2001) is important because the estimate for incurable items must be based on the assumption that all curable items are repaired.

Total Accrued Depreciation will then be given by: 


$$
1-((1-x) \times(1-y))
$$

Where $x$ is the rate of depreciation for curable physical deterioration and $y$, rate for age and functional obsolescence

\section{Illustration}

To illustrate how the approach being proposed could work, consider property that is 20 years old and would require about $10 \%$ of Replacement cost as new to fix all curable defects. Functional Obsolescence is estimated at 5\% of cost. Total accumulated depreciation can be calculated as follows.

A strict application of the model will imply that a property's value will fall to zero after its economic life. This may in reality not be the case particularly if the property has been well maintained. The use of the valuer's judgment in such a case becomes very crucial. A case can also be made for the incorporation of residual

Table I: Components of Depreciation

\begin{tabular}{lcl}
\hline Item & $\begin{array}{c}\text { Depreciation For Subject } \\
\text { Property }\end{array}$ & Remarks \\
\hline Age & $11.48 \%$ & $\begin{array}{l}\text { Property is 20 years old. The } \\
\text { method adopted here is the } \\
\text { reverse sum of the years' digits and using } \\
60 \text { years as the useful economic lifespan. }\end{array}$ \\
& $5 \%$ & $\begin{array}{l}\text { Extra cost incurred as a } \\
\text { result of property inefficiency } \\
\text { is estimated at 5\% of cost over } \\
\text { the remaining life of property r. }\end{array}$ \\
$\begin{array}{ll}\text { Functional } \\
\text { Obsolescence }\end{array}$ & $\begin{array}{l}\text { Based on schedule of repairs } \\
10 \% \text { of cost will be required, } \\
\text { put property in a condition as } \\
\text { new. }\end{array}$ \\
Physical & $10 \%$ & \\
Deterioration & & \\
& & \\
\hline
\end{tabular}

value in the estimation of the age component of depreciation; that is the value the asset will have after its useful economic life.

The proper estimation of depreciation for valuation purposes within the cost approach to value estimate is of crucial importance not only in arriving at correct estimate of value but also has the potential to reduce the variation that usually exist between values declared by valuers on the same property. The three causes of depreciation of interest to appraisers are age, physical deterioration and functional obsolescence. The approach that this paper supports is one that explicitly incorporates all these elements in the process of estimating depreciation. Such an approach provides perhaps the valuer's best estimate of accumulated depreciation for any particular property. We, however, suggest that a further study and discussion be carried out to explore the possibility of developing or adopting a single model that will allow for a more objective estimation of functional obsolescence and age.

\section{CONCLUSION}

$$
\begin{aligned}
& \text { Total Depreciation } \\
& =\quad 1-(1-0.1) \times(1-0.1648)) \\
& =0.2483 \\
& =\quad 24.83 \%
\end{aligned}
$$

52 Journal of Science and Technology, Vol. 29, No. 2, Aug., 2009 


\section{REFERENCES}

Barreca, S. L. (1999). Assessing functional obsolescence in a rapidly changing market place. Birmingham, U.S.A, Barreca Consulting and Research Inc.: 1-22.

Baum, A. (1991). Property investment, depreciation and obsolescence. Routledge, London: 21-30

Baxter, W. T. (1971). Depreciation. Sweet and Maxwell, London. 19-32

Brueggeman, W. B. and J. D. Fisher (2001). Real estate finance and investment.McGraw-Hill, Irwin. 45-97

Cannaday, R. E. and M. A. Sunderman (1986). "Estimation of depreciation for singlefamily appraisals." AREUEA Journal 14 (2): 225-273.

Corgel, J. B. and H. C. Smith (1981). The concept and estimation of economic life in the residential appraisal process. The Society of Real Estate Appraisers Foundation, U.S: 34-61

Follain, J. R. and S. Malpezzi (1980). Dissecting housing value and rent: Estimates of hedonic indexes for thirty-nine large SMA's. The Urban Institute, Washington D.C: $18-21$
Ghana Institution of Surveyors (1995). Guidance notes on valuation practice in Ghana. Presbyterian Press, Accra: 12-24

Hulten, C. R. and F. C. Wycoff (1978). "On the feasibility of equating tax to economic depreciation." Compendium of Tax Research: 91-120.

Jones, W. H., M. G. Ferri and L. R. McGee (1981). "A competitive testing approach to models of depreciation in housing." Journal of Economics and Business 33(3): 202211.

Mansfield, J. (2000). Much discussed, much misunderstood: A critical evaluation of the term obsolescence. The Cutting Edge. Windsor, RICS, London: 15-21

Raftery, J. (1991). Principles of building economics. BSP Professional Book, Oxford: $12-14$

Taubman, P. and R. E. Rashe (1969). "Economic and tax depreciation of office buildings." National Tax Journal 22(3): 334-346.

Wenzlick, R. (1953). "The probable life of single-family residences." Appraisal Bulletin: 17-20. 